\title{
CREATING A NEW, SUSTAINABLE MINDSET THROUGH RESPONSIBLE CONSUMPTION: A CASE STUDY OF THE INTERNATIONAL CHAIN OF SUSTAINABLE RESTAURANTS
}

\author{
Marek SERETNY*, Deepika GAUR**, Katarzyna SOBCZYK***, Maya KAABOUR**** \\ *American University in the Emirates, College of Business Administration, \\ Dubai, UNITED ARAB EMIRATES \\ e-mail: marek.seretny@aue.ae \\ **AL DAR University College, Dubai, UNITED ARAB EMIRATES \\ e-mail: deepika.gaur@aldar.ac.ae \\ ***Bareburger, Dubai, UNITED ARAB EMIRATES \\ e-mail:ksobczyk@bareburger.com \\ ****American University in the Emirates, graduating student of Marketing Specialization, \\ Dubai, UNITED ARAB EMIRATES \\ e-mail: m.kaabour@impactbbdo.ae
}

\begin{abstract}
This paper presents research conducted in the United Arab Emirates with the management of Bareburger, the chain of sustainable restaurants, as well as among its clients. In our project, we are interested in the relation between the offer of sustainability and the culture of conscious consumption. The opinions of industry experts and customers collected in an interview session are analyzed to derive the answer to the research questions. The research focuses on finding the possibility of changing the mindset and habits of consumers and creating an impact on consumer behavior by offering a responsible and sustainable nutrition model. An experiment was conducted to analyze the effect of sustainable restaurants on consumer culture in terms of cultivating healthy food habits. In our case study, we analyze Bareburger, a healthier fast-food chain that originated in the United States, which took the concept of sustainability to a completely new level, from ideation to implementation. Observing this process, we checked whether the unhealthy eating habits that we observe in the Middle East can be changed through the carefully composed model of a responsible restaurant.
\end{abstract}

Keywords: sustainable lifestyle, mindset, conscious consumption, organic, health-conscious consumers, sustainable marketing.

JEL Classification: M3, M30, M31, M39.

\section{$1 \quad$ Introduction ${ }^{1}$}

Today's world is facing a lot of serious problems; poverty, climate change, and various diseases are just the tip of the iceberg. One of the most serious challenges confronting humanity is the quality of food. The production and consumption of food are major challenges for sustainable development, and therefore, finding ways to change this situation, e.g., by changing consumer behavior, is becoming a key task for the industry and academia (Hedin, et al., 2019). For the past few decades, scientists have been paying attention to unhealthy consumption

\footnotetext{
${ }^{1}$ This article was submitted at the Digital Economy - Management, Innovation, Society \& Technology Conference 2020 (DEMIST'20), November 17, 2020 (http://demist.eu/).
}

habits, especially eating habits (Verplanken and Faes, 1999).

In the Middle East and North Africa, obesity is already a health issue. According to the World Health Organization (WHO), 2.3 billion people in these regions are overweight and 700 million are obese (Kilpi, et al., 2013). People in these regions have been experiencing a nutritional transition from a typical Arab diet to an unhealthy Western fast-food pattern. As a result, the eating habits of the younger generation have been affected; this is the reason for overweight and obesity appearing increasingly more often in the region (Yahia, et al., 2008). Scientific observation of global phenomena in relation to the Middle East shows that this situation leads to serious social, and finally economic, consequences. In this context, WHO's Technical Report Series 
No. 916 (TRS 916) is alarming and presents recommendations to help prevent death and disability from major nutrition-related chronic diseases. WHO calls for the development of regional strategies and national guidelines to reduce the burden of diseases related to obesity, diabetes, cardiovascular diseases, various forms of cancer, osteoporosis, and tooth diseases. Implementing responsibility in business operations is, on the one hand, a moral and ethical duty; on the other hand, responsibility pays off, as an economically responsible business brings profit. Sustainable entrepreneurship is a concept that combines both sustainability and entrepreneurship, and it has been defined as "an innovative, market oriented and personality driven form of value creation by environmentally or socially beneficial innovations and products exceeding the start-up phase of a company" (Iyigun, 2015).

Companies trying to keep up with the changing role of management define and embody their values in the products that they offer their clients, implementing the principles of sustainability. They also analyze the effect of value-based management on employees, partners, or stakeholders. Sustainable entrepreneurs act as catalysts for transitioning from the current economy to a sustainable economy. The overarching goal is to make the world better through shared responsibility and respect for the common good. Increasing market awareness requires emphasis on internal values, spirituality, and culture, as well as more intensive cooperation with the community. According to the 2019 Euromonitor Consumer Trends report, there is a global trend of healthconscious consumers toward consumption of products that will leave little damage to both their bodies and the environment (Angus and Westbrook, 2019). Kubacki, et al. (2015) present a review of research indicating the effectiveness of implementing social marketing in the area of changes in problematic behavior. The authors argue that social marketing activities successfully contribute to creating positive behavioral changes. The results of marketing activities affect not only immediate and short-term behaviors but also bring about long-term changes in attitudes, behavioral intentions, and/or awareness.

Change in marketing awareness toward "sustainable marketing" is on the rise, and many brands are jump- ing on the "responsibility" bandwagon to gain popularity and achieve loyalty with their customers. In our case study, we analyze Bareburger, a healthier fast-food chain that originated in the United States and that took the concept of sustainability to a completely new level, from ideation to implementation (Roman, 2017). Wroblewski, et al. (2019) state that, "The concept of sustainability offers a new framework for redesigning cultural policies and revisiting cultural management methods through a comprehensive approach that encompasses care for the environment, develops practices for sound management of public resources and brings the concept of social responsibility to the forefront."

Sustainable culture requires a sustainable mindset; following Kassel, et al. (2016), we can define the Sustainable Mindset as an incorporation of three dimensions, namely, values (being), knowledge (thinking), expressed in the actions (doing). Therefore, "Sustainable Mindset is a way of thinking and being that results from a broad understanding of the ecosystem's manifestations as well as an introspective focus on one's personal values and higher self and finds its expression in actions for the greater good of the whole." For the purposes of our project, we can assume that the responsible producer or service provider, as well as the consumer, understands and recognizes the interrelationships between the various components of our ecosystem and the complexity of the impact of human behavior on the system as a whole. However, "introspective focus on personal values" - as the authors of the definition state - refers to the self-awareness of professed values and the values in action as they relate to our sustainable or unsustainable behavior.

The definition also refers to the inclusion of a spiritual dimension and consideration of the purpose, meaning, and unity of our behaviors. Finally, we should understand that the Sustainable Mindset drives not only altruistic or philanthropic actions but also entrepreneurial or business actions that include and serve all stakeholders' interests, including those of our planet and future generations (Kassel, et al., 2016).

Based on our academic and business experience and after analyzing current literature, we would like to 
conclude that a Sustainable Mindset present on the business side can influence consumer behavior.

\section{Conscious Consumption}

Consumption is a basic necessity of life. The process of producing, exchanging, and acquiring goods has accompanied humanity practically since the beginning of its existence, thus becoming one of the most important spheres of social activity (Seretny, 2018). On the other hand, consumption in its extreme form of overconsumption, or even hyperconsumption, has become one of the main problems of the modern world (The Economist, 2012). Calls for a transformation toward more sustainable, conscious consumption have been intensifying (Cohen and Munoz, 2016). Encouraging change toward more sustainable ways of living and consuming is a complex process (Watkins, et al., 2016).

The role of marketing in conscious consumption is becoming more important than ever before. This field, influenced by the concept of sustainability, is able to reestablish its assumptions, theories, tools, and systems to influence the market and make consumption decisions possible. Marketing leaders, being aware of their responsibility, should know how to use marketing tools to effectively move from the sales expansion paradigm to creating a conscious, responsible customer (Seretny, 2018). Agricultural and food production processes contribute the most to the negative environmental impact. Thus, the choice of food and diet is important for sustainable consumption, from the point of view of food preparation and production, as well as other socioeconomic factors, such as public health or cohesive social development (Nemeth, et al., 2019).

The Bareburger website itself can give an inside look on what the brand is trying to achieve. The company uses slang English and hip colors in an effort to make sustainable living look like the "cooler" thing to do. The website also narrates the company's story from the inception of the burger as a cow eating grass, to its delivery in biodegradable packaging. The company has also worked on having mostly plant-based items on its menu to cater to those who are already living sustainably but do not want to compromise on taste (Bareburger, 2019).
According to an article written in the Mobile Marketer, Bareburger is also playing around the insight that food photography can usually glamorize food, making it look much better than it does in real life. Hence, it has created augmented reality menus and gamified the concept of taking pictures of your food by asking consumers to participate in building a realistic menu. Such efforts make it obvious that not only is the brand extremely forward thinking, but it also capitalizes on existing behaviors of millennials, who are obsessed with their phones, to create a memorable experience for them (Williams, 2018).

That is not to say that the brand has never received any bad press. In 2018, an article in The New York Times, titled, "When the Menu Says 'Organic' But Not All The Food Is", written by Priya Krishna (2019), exposed all restaurants in the United States and showed how there are no strict regulations on what qualifies as truly organic.

A man investigating the authenticity of Bareburger's claims said that he had found nonorganic mayonnaise and ketchup packages in the trash outside the restaurant. However, despite the backlash, people said that they were fine with a restaurant being $70 \%-$ $80 \%$ organic, as organic refers more to the sustainable marketing process as a whole. They said that it would be better to dine at a restaurant that is $80 \%$ organic with its meat and $100 \%$ sustainable in its production process than to go somewhere that serves fully organic food but pollutes the planet (Krishna, 2018).

The fact that this polarizing article went out on one of the most well-known publications in the United States and people are still big fans of Bareburger is proof to how loyal fans are difficult to sway and that they stay around for the long term. Giving sustainability another definition, Bareburger also collaborated with a discount platform called Unidays, targeting university students to provide them with discounts on their meals (Fast Casual, 2018). This was a smart tactic for them in terms of harnessing the organic mindset in consumers such as the Gen $\mathrm{Z}$, who are not yet very financially capable but will be in the very near future. 


\section{Research and Analysis}

The research on which this paper is based was conducted in order to answer the following research question: Is it possible for food-conscious consumption to bring about a change of mindset?

In the process of collecting data, discussions were held with two focus groups. Of the two focus groups, one comprised representatives of the young generation; the other focus group comprised Bareburger representatives, with the discussion in the form of an interview.

The case study and analysis were developed as a result of cooperation between business and academia. Students of marketing had a significant part in compiling this case study. Their opinions, as those born and raised in the United Arab Emirates (UAE), contributed immensely to the analysis of consumer behavior. An interview with the management of Bareburger in Dubai was also conducted. Data on the business model and its clients, provided by Bareburger's management, were analyzed.

\subsection{Exposure of Dubai's Young Generation to the Sustainability Mindset}

Interviews were conducted from October 13, 2019 to October 27, 2019, with a set of residents of the UAE who were $\leq 30$ years of age. Their nationalities varied from Egyptian with American citizenship, to Saudi, English, Iranian, Lebanese, and even Palestinian. The interviewees were asked about their interpretation of "sustainable living" and "conscious consumption". They were also asked about what sustainable habits they grew up with, if any, and whether they consume any sustainable brands or are aware of any of the current global or local sustainability efforts that caught their attention.

It was interesting to find that most respondents viewed sustainability as a matter relating mostly to not harming the environment and were not aware of other aspects of it pertaining to profit or people. Most of them knew what it took to live a sustainable life but blamed not doing so on the lack of infrastructure in the UAE. The statements of students who are influenced by the modern global market show a real state of awareness of responsible behavior in relation to conscious consumption. "I don't even have a recycling bin in my building, and I live downtown. I don't feel that there are any simple efforts being put in place to encourage sustainable living in a place as progressive and technologically advanced as Dubai", said Salma Shahin. "When I first moved here, I did not pay attention to the way I was living. I would throw my garbage in a garbage shoot and not pay attention on where that goes. Only in recent years I started to try myself, and the solutions aren't readily available", said Emma Randall. An interesting observation is that among young people, the concept of "organic" arouses consternation and is interlinked to the idea of "sustainability", although what is organic is not necessarily produced in a sustainable manner.

\subsection{Bareburger Analysis}

Bareburger's mission is "to take a simple, joyful, and organic approach to food", and its vision is "to build a better food system of one burger at a time" (Bareburger, 2019). It is clear that the brand wants to position itself as a $100 \%$ organic and natural food chain. However, as mentioned by its restaurant manager, from its Dubai office, the challenge becomes more about changing the mindsets on sustainability in places such as the UAE, where green living is not part of the culture or the upbringing. As is the case with every brand that takes the full plunge toward a new trend, Bareburger is taking many calculated risks to leave its brand's footprint in the world. This could result in many hits and misses, but so far, the brand is basking in its hard-earned fame.

Bareburger first opened its doors in 2009 at the small corner of Astoria, Queens, New York. Surprisingly, in the time of recession, the restaurant was fully packed with customers lining up to try the organicsourced and sustainable burgers from the day of opening. The restaurant's vision is to serve local and organic food in the closest neighborhood. For people to pay $\$ 11$ or $\$ 12$ in 2009 for a burger when "we're in the middle of a recession, that really struck a chord", said Pelekanos, who also serves as the chief executive. "People were just starting to care about where their food came from." As an early adopter of local, sustainable ingredients, the eatery resonated even more with consumers. Within 8 
months of Bareburger's debut, a second outlet opened in Greenwich Village. The chain now has 28 stores, 17 of which are in New York City. It has expanded to Japan, Germany, and the UAE. About half are franchises, although the company intends to focus on corporate-owned sites in the coming months.

Pelekanos expects to open 16 more restaurants by mid-2017. "Bareburger identified an emerging trend in the mainstream public to eat 'better for you' foods but with an unwillingness to give up what they love, burgers," said Arlene Spiegel, a restaurant industry consultant. The company has followed a time-tested model of perfecting its local marketing and operating systems before franchising its brand, she noted. One growing pain has been finding honest food distributors operating all-natural farms near the new eateries. "It's such an integral part of our business," Pelekanos said. "The product is the product, and you have to verify that it is what they say it is".

The Organic Consumers Association (OCA) and Bareburger announced Bareburger's launch of a new initiative aimed at providing consumers with full transparency about the origin, nature, and quality of the food that they eat at Bareburger restaurants.

As claimed by the Bareburger management, the sustainability efforts go beyond its food. Each Bareburger unit is built with reclaimed and recycled materials, making every one of its vibrant spaces unique. The Bareburger approach to food is simple, fun, and organic. Fresh, live, clean ingredients make good food, and good food in an enjoyable and happy space can make the corner of the world where a restaurant is located so much better. Restaurant staff and management take pride in preparing and cooking food, as well as in getting to know the farmers who grow the offered products. Summarizing the interview, Bareburger representatives stated: "We cook fresh, and we serve fresh. So, whether you are health-conscious, environmentally conscious, or simply love great grub, we've got something on our menu that will make you smile."

Summarizing, we could see what factors are working in Bareburger's advantage and which ones are not. Sustainability, as a trend, is growing. It will undoubtedly attract many motivated employees. Bareburger needs to implement long-term thinking within its organization. Yes, consumers are now enjoying the brand because it is the only fully sustainable one; but how does the company plan on standing out when sustainable marketing becomes the norm?

Bareburger is the first fast-food chain to cover sustainability in all its pillars (economic, environmental, and social), which provides it with an edge and firstmover advantage.

There will always be news outlets and consumers who try to find loopholes in the brand's "organic" claims. How will it convert them into brand loyalists or still use their bad press to its advantage?

\subsection{Bareburger's Target Market}

Bareburger targets many different types of audiences that all have one thing in common: they are conscious of the products that they are consuming. Its announcement on the website addresses "veggie heads", "gluten-lovers", and "carnivorous" burger lovers (Bareburger, 2019). It is also clear from its augmented reality efforts and campaigns that the company is targeting Gen $\mathrm{Z}$ and Gen $\mathrm{Y}$ - both of whom value the importance of a cool product and the cool experience that comes along with it (Williams, 2018). Bareburger does not limit itself to serving only meat items; due to increasing health consciousness, recently, it has introduced in its menu Beyond Burger and Impossible Meat, the first plant-based meat satisfying their customer's craving for meat and ecological concerns. The company says that Impossible Meat uses $95 \%$ less land and $74 \%$ less water for production, and it emits about $87 \%$ less greenhouse gas than a ground beef burger patty. There are also many health benefits such as zero cholesterol and high protein levels - the same amount that you would find in a comparable cut of beef patty.

\subsection{Bareburger's Strategic Approach}

Sustainability covers various pillars: "The greatest realization brands must make is that sustainability goes beyond caring for the environment. It involves three major aspects - environmental, economic and social - each of which must be taken into consideration for a true sustainability strategy" (Lein, 2018). This is part of Bareburger's strategy, to introduce the concept of sustainability in everything that the com- 
pany does, and the effect that its activities have on people and the environment after its products are consumed. Bareburger's aim is to create organically prepared food that burger lovers consume consciously. Its products vary from meat burgers to $100 \%$ plant-based burgers. Regardless of which option the client chooses, the client can be sure that the product is clean, organic, and healthy. The price of the burgers may be more expensive compared to other fastfood chains, but this is expected since customers are getting more value for their money.

The locations of the restaurant's branches adhere to a specific proximity radius to their suppliers to ensure that the vegetables are as fresh as possible. The chain has collaborated with the likes of Beyond Meat to make all vegan burger lovers' dreams come true. Bareburger's stores are built entirely from recyclable materials, and they use biodegradable packaging to deliver their food, be it the napkins or the cutlery (Bareburger, 2019).

In terms of promotions, the company has collaborated with food discount platforms such as Unidays in the United States and Zomato in the UAE to encourage slightly more-price-conscious consumers to try the product (Fast Causal, 2018). It has also experimented with digital branding and augmented reality to promote its products in a fun way. Sustainability is also a mindset and Bareburger has embraced this concept - sustainability means to find joy in what you do and give joy to others while you are doing it (Williams, 2018).

Mindset is the way in which an individual interprets the stimulus around him/her in relation to all the information and experience gathered so far about the surroundings. The sustainability mindset involves having a tendency to analyzing the results of our everyday actions on the environment and being concerned about the positive or negative effects thereof.

This mindset is being explored by Bareburger, and it has developed an approach to intervene in this mindset of consumers and bring awareness about the effects of their eating habits. As consumer awareness increases, what is unavoidable is that consumers will not only consider, but also demand, more sustainable choices. Accordingly, businesses should anticipate their needs wisely.

\section{Discussion on an Effective Strategy for the UAE}

A brand such as Bareburger opening up in a country like the UAE needs to put in increased effort on not only marketing its presence but also educating consumers on the importance of sustainability, more than it would have had to do in the United States. The Unite Nation's Sustainable Development Report HELP2018 reads as follows: UAE's commitment to sustainable development is at the heart of the country's vision for its future and the ideas of sustainable development permeate UAE's national development plan - Vision 2021; however, consumer awareness is still far from expectation.

The interviews show that consumers have a perception that anything sustainably produced is "ridiculously expensive". Every day, consumers are bombarded with varied information about numerous products and services, based on which they make a purchase decision. Contrary to appearances, this is not an easy decision, especially when the consumer tries to make his/her choice beneficial both for $\mathrm{him} / \mathrm{her}$, in terms of quality and price, as well as for the environment, and, at the same time, consider social and ethical criteria too.

Our analysis of sustainable consumption points that there is a gap in consumer knowledge, as well as a weak belief in the real impact that consumers have, through their behaviors and habits, on the environment in which they live. In general, the opinion is that the authorities, both at the state and the local levels, are responsible for the state of the environment. The responsibility of every citizen in this matter is not perceived so clearly. Consumers are different: they have different needs, they lead different lifestyles, and often, through consumption, they try to express their personality and social status and maintain or improve their quality of life. Every consumer should have the right to enjoy free choice of goods and services, but it is important that this choice be made with the awareness of the consequences that it brings. Building consumer awareness is a long-term process, and the most effective tool is education and information. Education from an early age gives hope that a generation of consumers equipped with knowledge will grow, and this 
knowledge will allow them to make rational choices that are beneficial for them, for society, and for the environment.

Understanding the principles of sustainable development - and the associated concept of sustainable consumption - can encourage consumers to analyze the structure of their needs and introduce conscious changes in their lifestyle. In the era of "lifelong learning", educational activities should be diverse and directed toward all social groups. As has been said before, educational programs for children and young people, which should be part of school programs, will be the most effective. The participation of the youngest in the family decision-making process is systematically increasing, and young consumers themselves constitute a large purchasing power. Children are also carriers of information in the family, as a result of which, often, older family members modify their habits.

They can also collaborate with relevant influencers in the UAE who already have a heavy following for all things related to nutrition and healthy lifestyle, such as Zoe Happy Fit or Diana Madness. According to an article in Adweek, consumers are not weary of influencer marketing just yet. They are just tired of influencer marketing that feels like a forcefit. It is essential for brands to find influencers that fit their brand identity and build a long-term relationship with them to appeal to consumers as authentic and transparent (Shaftel, 2019). Another thing Bareburger can do in the UAE is focus its efforts on targeting the youth, namely, Gen Y and Gen Z, who are more likely to adapt to changes in lifestyle, unlike the baby boomers.

\section{Conclusion}

Bareburger definitely has a competitive advantage in being the first fast-food chain that thinks way ahead to foresee what our future will look like. It has introduced sustainability in everything that it does and is attracting numerous customers around the world. For it to remain successful in the future and be able to expand into markets where sustainability is not that much of a priority, it will definitely have to educate the world on why sustainability is important and why it believes in sustainability. It should also keep working on its efforts at communicating the concept to Gen $\mathrm{Z}$ and Gen Y customers, on platforms that they use, with stories that are engaging and relevant, making them truly feel like they are making the world a better place one burger at a time.

Based on our research, we believe that through conscious marketing communication, the company has been able to build new consumer awareness and create new habits that induce consumers to change consumption attitudes. Well-formulated social marketing communication should act as a wake-up call to us, warning that our current lifestyle is harming the planet.

\section{$6 \quad$ References}

[1] Angus, A., Westbrook, G., 2019. Top 10 Global Consumer Trends 2019. Euromonitor International. [online] Available at: https://go. euromonitor.com/white-paper-EC-2019-Top-10Global-Consumer-Trends.html [Accessed 20 January 2020].

[2] Armstrong, T., 2019. Diet, nutrition and the prevention of chronic diseases - Report of the joint WHO/FAO expert consultation. WHO Technical Report Series, No. 916 (TRS 916) [online] Available at: https://www.who.int/ dietphysicalactivity/publications/trs916/summar y/en/. [Accessed 18 February 2020].

[3] Business Wire, 2017. Bareburger becomes the first-national restaurant chain to start delivery of the impossible burger. Press release: (2017, Nov 20). [online] Available at: https://www .businesswire.com/news/home/20171120006159 /en/ADDING-MULTIMEDIA-Bareburger-Beco mes-the-First-National-Restaurant-Chain-to-Sta rt-Delivery-of-the-Impossible-Burger. [Accessed 19 January 2020].

[4] Fast Casual, 2018. Bareburger hooks up with unidays to target gen $\mathrm{Z}$ customers. Fast Casual. News Features [online] Available at: https://www.fastcasual.com/news/bareburgerhooks-up-with-unidays-to-target-millennial-genz-customers/ [Accessed 22 January 2020].

[5] Cohen B., Munoz P., 2016, Sharing cities and sustainable consumption and production: towards an integrated framework. Journal of 
Cleaner Production, Volume, 134, Part A, pp.87-97.

[6] Hedin B., Katzef C., Eriksson E., Pargman D., 2019. A Systematic Review of Digital Behaviour Change Interventions for More Sustainable Food Consumption. Sustainability 11(9), 2638. https://doi.org/10.3390/su11092638. [online] Available at: https://www.mdpi.com/20711050/11/9/2638 [Accessed 2 February 2020].

[7] Iyigun, N.O., 2015. What could Entrepreneurship do for Sustainable Development? A Corporate Social Responsibility-Based Approach, Procedia. Social and Behavioral Sciences, 195, pp.1226-1231.

[8] Kassel, K., Rimanoczy, I., Mitchell, S., 2016. A Sustainable Mindset Model for Management Education [online] Available at: https:// www.researchgate.net/publication/325746486_A _Sustainable_Mindset_Model_for_Management _Education, [Accessed 15 February 2020].

[9] Kilpi, F., Webber, L., Musaigner, A., AitsiSelmi, A., 2013. Alarming predictions for obesity and non-communicable diseases in the Middle East. Cambridge University Press, https://doi.org/10.1017/S1368980013000840.

[10] Krishna, P., 2018. When the Menu Says 'Organic,' but Not All the Food Is. [online] https://www.nytimes.com/2018/08/13/dining/org anic-label-restaurants-bareburger.html [Accessed 25 January 2020]

[11] Kubacki, K., Rundle-Thile, S., Pang B., Buyecek, N., 2015. Minimizing alcohol harm: a systematic social marketing review (2000-2014). Journal of Business Research, https://doi.org /10.1016/j.jbusres.2015.03.023.

[12] Lein, S., 2018. Why Sustainable Branding Matters. Forbs [online] Available at: https://www.forbes.com/sites/theyec/2018/08/20 /why-sustainable-branding-matters/\#6b0654335 b6e [Accessed 23 January 2020]

[13] Nemeth, N., Rudnak, I., Ymeri, P.,Fogarassy C., 2019. The Role of Cultural Factors in Sustainable Food Consumption - An Investigation of the Consumption Habits among International Students in Hungary. Sustainability, 11(11), 3052; https://doi.org/10.3390/su11113052.

[14] Bareburger. (n.d.). Our Story - Bareburger. Bareburger. [online] Available at: https://www. bareburger.com/our-story/ [Accessed 10 January 2020].

[15] Seretny, M., 2018. Sustainable management marketing perspective: essence, determinants and manifestations. Warsaw University of Technology Publishing House, ISBN 978-83-7814769-5.

[16] Shaftel, L.M., 2019. A Long-Lasting Relationship Between Brands and Influencers Radiates Authenticity. [online] Available at: https://www.adweek.com/brand-marketing/along-lasting-relationship-between-brands-andinfluencers-radiates-authenticity/ [Accessed 19 January 2020].

[17] UAE Government, 2020. The UAE's response to climate change. UAE Government [online] Available at: https://government.ae/en/informa tion-and-services/environment-and-energy/clima te-change/theuaesresponsetoclimatechange, [Accessed 19 August 2020].

[18] Verplanken, B., Faes, S., 1999. Good intentions, bad habits, and effects of forming implementation intentions on healthy eating. European Journal of Social Psychology, vol. 29, issue 5-6 pp. 591-604. https://doi.org/10.1002/(SICI)10990992(199908/09)29:5/6<591::AID-EJSP948>3. $0 . \mathrm{CO} ; 2-\mathrm{H}$.

[19] Watkins, L., Aitken, R., Mather, D., 2016. Conscientious consumers: a relationship between moral foundations, political orientation and sustainable consumption. Journal of Cleaner Production, Volume 134, Part A, pp. 137-146.

[20] Williams, R., 2018. Bareburger's AR menu brings fresh meaning to 'playing with food'. [online] Available at: https://www.mobile marketer.com/news/bareburgers-ar-menu-bringsfresh-meaning-to-playing-with-food/521804/ [Accessed 25 January 2020].

[21] Wroblewski, L., Gaio, A., Rosewall, E., 2019. Sustainable Cultural Management in the 21st Century. Sustainability, Special Issue pp 1-6, [pdf] Available at: https://www.mdpi.com/books /pdfview/book/1876, [Accessed 12 February 2020].

[22] Yahia, N., Achkar, A., Abdallah, A., Rizk, S., 2008. Eating habits and obesity among Lebanese university students, Nutrition Journal, 7:32, https://doi.org/10.1186/1475-2891-7-32. 